\title{
THE ORIGINS OF THE REMOTE FUTURE FORMATIVES IN KINYARWANDA, KIRUNDI AND GIHA (J61)*
}

\author{
Robert Botne \\ Indiana University
}

\begin{abstract}
Among the interlacustrine languages of eastern Africa Kinyarwanda, Kirundi and Giha have been classified in Bastin [1978] as dialects of the same language, identified in the zone classification system as J61. While it is certainly debatable whether or not they should be considered to constitute a single language, this classificaiton clearly reflects the high degree of similarity and mutual intelligibility found among these three languages. Given the very close correspondences that we do find, in particular among the basic tense formatives and their meanings, it is of special interest that the remote future formatives in these languages differ as much as they do in phonological form: -za:- in Kinyarwanda, zo:- in Kirundi, and -ro- in Giha. Just as perplexing is the apparent lack in these languages of a future formative of the general form $-l i-$, a form characteristic of nearly every other language in zone J. My objective in this paper is to describe and trace the probable development of these various forms of the remote future marker and, in so doing, demonstrate that they do originate in the same source as the more common form -li-.
\end{abstract}

\section{Introduction}

A long-standing, and seemingly unquestioned, belief about the remote future formative in Kinyarwanda, Kirundi and Giha (J61 in the Tervuren classification system, see maps 1 and 2), dating at least as far back as van der Burgt's [1902] sketch of Kirundi, is that the source of this formative is to be found in the auxiliary verb 'come'. It is not difficult to understand why this analysis has been

\footnotetext{
* I would like to thank Enoch Mvula (Chichewa), Louise Kahindo-Katalonge (Kinande), Firmard Sabimana (Kikrundi), Providence Musomandera (Kinyarwanda), and George Mhechela (Chigogo) for their assistance and insightful comments about their languages. I particularly thank Paul Newman, Russell Schuh, and Derek Nurse for comments and critical evaluation of the analysis presented here. The position taken here does not necessarily represent their views.
} 
so readily and widely accepted: the form of the remote future formative in many eastern Bantu languages resembles, to a greater or lesser extent, the form of the verb 'come'. However, we cannot assume a priori that because the two forms resemble one another that one is derived from the other, particularly when the resemblance is only partial. In the case of the languages in J61 I will argue that auxiliary 'come' is not the source of the remote future marker; rather, sound changes have occurred that have resulted in 'come' and the remote future formative having a similar form.

\section{The Remote Future Formative and the COME Hypothesis}

In general the three languages of J61-Kinyarwanda, Kirundi, and Gihashow very close correspondences in form and meaning in most verbal constructions. The remote future (RF) construction stands out because of the relatively wide range of variation found in the form of the tense formative, as illustrated in (1).
$\begin{array}{ll}\text { (1) a. } \text { Ba-za:-tem-a } & \text { igiti } \\ \text { 3P-RF-cut down-FV tree }\end{array}$
Kinyarwanda
'they will cut down the tree'
$[\mathrm{FV}=($ stem $)$ final vowel $]$
b. Ba-zo:-tem-a amáshaka
Kirundi
3P-RF-cut-FV sorghum
'they will harvest the sorghum'
c. $\beta$ a-ro-kor-a
3P-RF-work-FV
'they will work'
Giha: Sambeek n.d.

The RF formative in Kinyarwanda and Kirundi resembles the verb $k u-: z a$ 'to come' (root = -:z- ), a fact noted very early by Hurel [1911] for Kinyarwanda and van der Burgt [1902] for Kirundi. Hurel lists two future constructions for Kinyarwanda: one (2a) a periphrastic construction involving auxiliary 'come' plus the infinitive, the other $(2 \mathrm{~b})$ incorporating $-z a(:)$ - as a prefix. He considers these two occurrences of $-z a(:)-$ to represent one and the same auxiliary element.

(2) a. a-za gu-kora 'he will work (later today)'

b. a-za-kora 'he will work (after today)'

(N.B. tone and vowel length are not marked by Hurel) 
Both constructions continue to exist in modern Kinyarwanda. Van der Burgt, in a similar vein, states quite categorically with respect to Kirundi that the RF formative "est l'auxiliaire essentiel pour le temps futur et dérive indubitablement de $k u-z a=$ venir" [1902:43].

Analysis of the verb 'come' as the source of the RF formative is widespread in descriptions of other eastern Bantu languages as well. The examples in (3-7) attest to a few of the instances that can be found in the literature.
(3) ni-za-et-a
Pare G22
[Nurse 1979a]
1S-F-bring-FV
'I will bring (it)'
-z- 'come'
(4) tu-tso-yul-a
Luguru G35
[Nurse 1979b]
1P-F-buy-FV
'we will buy'
-tsa 'come' ( tsa +o>tso )
(5) a-ka-ísáá-boomb-a
Chibemba M42
[Givón 1969]
3S-F-RF-work-FV
'he'll work later on'
uku-isa 'to come'
(6) m-dzá-won-a m ma: $\hat{\text { wa }}$
2P-RF-see-FV in morning
Chichewa N31
[Watkins 1937]
'you'll see in the morning'
$k u: d z a$ 'to come'
(7) u-do-zwim-a
3S-F-hunt-FV
Venda S21
[Zierfogel 1961]
'he will hunt'
$u-d a$ 'to come' $(d a+u-($ inf $)>d o)$

Given the pervasiveness of the phenomenon, analysis of Kinyarwanda -za:- and Kirundi -zo:- as originally derived from auxiliary 'come' seems, at first glance, both straightforward and quite appealing. Nevertheless, as seductively simple and explanatory as the 'come' hypothesis might appear, there are several disturbing observations that suggest problems with such an analysis. First, the verb 'come' in Kinyarwanda either has the vowel /i/ initially (for example, when preceded by the reflexive prefix (- $\hat{\imath}:-)$ or produces lengthening of the preceding vowel, as the examples in (8-9) attest, whereas the RF formative never appears with an initial vowel nor does it produce vowel lengthening. 

(8) $k w-\hat{\imath}: y-i z-i r-a$
'to come oneself'
(9) a. $k u-: z-a$
'to come'
b. a-ra-:z-a
'he/she will come (later)'
c. $\beta a-: z-a$ Buri mu:nsi
'they come every day'

Second, -:z- 'come' is not followed by a long /a:/ in derived compounds as are other monosyllabic verbs such as -tá 'abandon, break off (habit)' (compare 10a and 11a). Nor does -:z- exhibit a long /a:/ when followed by another morpheme, such as the associative suffix -an-, whereas -tá does (compare (10b) and (11b)). The RF formative always exhibits long /a:/; hence, even if the source were $-: z_{-}$, something would have to have been added to produce the observed lengthening.
a. umu-:za-joro $-: Z-\quad$ 'come' ijoro 'night'
'rain that begins at night and is prolonged'

b. $k u-: z-a n-a$

'to come with; bring'

(11)
a. în-tá:-bê:re -tá 'abandon' ißê:re 'breast'

'child weaned too early'

b. gu-tá-an-a

'to separate oneself from, break with (something)'

Third, the verb -:z- is always low-toned, whereas the RF formative has an underlying high tone [Overdulve 1975, Botne 1983] which is realized on the surface only in certain constructions such as the negative.
ejó
nti-ßá-zâ:-kor-a mu rúgo
tomorrow NEG-3P-RF-work-FV in compound
'tomorrow they will not work in the compound'

Fourth, Kinyarwanda and Kirundi are in an area where the predominant RF formative is a reflex of $-1 i-$; no other languages in the area appear to have a reflex of 'come' as a future formative, though some, such as Orusyan (J36) and Lumasaba (J31), have developed a future formative from the auxiliary -kanga/-kana 'want, intend'. 
While these observations are not in themselves sufficient reason to reject the 'come' hypothesis outright as the source of the remote future markers -za:- in Kinyarwanda or -zo:- in Kirundi, they do suggest that a closer examination of the phenomenon is warranted. In the following sections, then, we consider alternatives to the 'come' hypothesis that provide a much more satisfactory explanation of the data.

\section{2. -li- as Source of the Remote Future Formative}

The majority of languages in zone $\mathrm{J}$ express the remote future through the use of a variant form of -li-. The following examples illustrate the various forms that $-1 i$ - has assumed in these languages.
(13) a-li-tu-laba
Luganda J15
[Ashton et al. 1954]
3S-RF-1P-see
'he/she will see us'
(14) a-ri-gonza
Ruziba J22
[Rehse 1912]
3S-RF-love
'he/she will love'

a-rya-gura ebintu
3S-RF-buy things
'he/she will buy things'
Runyankore J11 [Morris and Kirwan 1972]

Of particular relevance for the analysis of Kinyarwanda -za:- is the example in (15) from Runyankore, a language bordering Kinyarwanda on the north. In Runyankore we find the form -rya-, which can be further analyzed as $-\mathrm{ri}+\mathrm{a}-$. Such an analysis is confirmed by the relative and negative RF constructions in which we find only the formative -ri-, as in (16). (Note that the use of "(" in the examples indicates deletion of following vowel, ")" deletion of a preceding vowel.)
(16)
a. o-ri-gura...
Relative
[Morris and Kirwan 1972]
3Srel-RF-buy
'he/she who will buy...' 


\section{b. t(i-a-rí-gura ebintu Negative NEG-3S-RF-buy things \\ 'she will not buy things'}

The relevance of the formative -a-for the present analysis is not to be found in its function (which is unclear), but in its areal distribution. In addition to Runyankore, we also find it in Lunyoro J11 (see Mould [1981]), Karagwe J21, and perhaps in Mashi J53 general future -aa- [Polak-Bynon 1975] (see map 3 in Appendix). That Kinyarwanda also incorporates this formative can be seen from a comparison of the basic tense formatives in the remote past, recent past, present/near future, and remote future [Botne 1983].

Kinyarwanda tense formatives

$\begin{array}{ll}\text { remote past } & -a+(\text { ra- }) \\ \text { recent past } & -a+(a-) \\ \text { pres/nf } & -\emptyset+\text { ra- } \\ \text { remote future } & -z V+a-\end{array}$

We may note here a pattern of regular alternation between -ra- and -a- in this sequence of tenses, rendering the segmentation of -za:- into two components quite appropriate. Kimenyi [1986] scoffs at this analysis as farfetched, arguing that -za:- is never segmented. However, he neglects to consider that the usage of -ra-/-a- in past constructions is determined by syntactic criteria, while in the nonpast they are obligatory. So while it is true that -za:- always occurs as an inseparable unit, we can see from this pattern of regular and systematic alternation of forms and from the fact that neighboring languages also manifest this -a-formative in the same environment that -za:- is a bimorphemic form derived originally from two distinct elements: $-z V$ - and $-a-$.

The question we must now consider is, "To what did this -a-become attached? Was it the auxiliary verb -:za 'come' as traditionally hypothesized? Or was it something else?" I suggest that it was not -:za, but rather -zí-, a form derived phonologically from -rí-through spirantization. What is crucial for this analysis is the original nature of the vowel, a high close / $i$ / or the non-close /i/. Guthrie [1971] reconstructs *-di- (non-close) as the RF formative in his comparative series CS2245. However, although most of the languages of zone $\mathrm{J}$ have shifted from a proto-Bantu seven vowel system to a five vowel system in which the / $\mathrm{j} /$ and /i/ have collapsed together, Lulogooli (E41 in Bastin [1978], but considered part of the Greater Luyia group (J30) by Mould [1981]) has maintained the seven vowel system. And here we find $-r i$ - rather than $-r \iota-\left(*_{j}>i, *_{i}>\iota\right.$ [Mould 
1981:187]). This observation suggests that, in fact, the original form had the high, close $/ \dot{l} /$, a significant fact for phonological processes in Kinyarwanda.

In Kinyarwanda an $/ r /$ followed by a high, close $/ i /$ became spirantized. Consider, for example, the case of the class 5 nominal prefix which was originally $-r i-$. Before $\mathrm{C}$-initial stems the $/ r /$ became lost, a phenomenon also reported for northeast coast Bantu languages [Hinnebusch 1981]. Before V-initial stems the $/ r /$ became spirantized, as the examples in (18)-(19) attest.

$$
\begin{aligned}
& \left.i+3 \hat{i}+i \int o \quad-\quad a ́+m a ̂++i\right) s o \quad \text { 'eye/s' }\{<i-r i j-(y) i c o\} \\
& \text { a. í+zi+iko - a+má+zî:ko 'hearth/s' }\{<i-r i-(y) i k o\} \\
& \text { b. } 1+\text { +z(îturu - a+má+zû:ru 'nose/s' } \quad\{<i-r i-(y) u l u\}
\end{aligned}
$$

Subsequently the $/ z /$ became reanalyzed in some instances (as in 19) as part of the stem. Such reanalysis is not limited to Kinyarwanda, but occurs in other eastern Bantu languages as well. Hetherwick [1914], for example, records an alternation in Chinyanja (N31) plural forms of class 5 nouns in the process of being reanalyzed that mirrors that observed for Kinyarwanda.

\section{(20) $d z($ i) +ino - ma+no $\sim$ ma+ino $\sim$ ma+dzino 'tooth/teeth' Chinyanja N31}

From the example in (19b) we see that the vowel /i/ of the prefix in Kinyarwanda is lost with subsequent lengthening of the following vowel, in this instance $/ u /$. It is this path of change, I believe, that is responsible for the present form of the RF formative in Kinyarwanda. The formative $-r_{\mathfrak{l}}$ - was followed by $-a-;$ in this environment the $/ r /$ became spirantized and the $-a-$ lengthened in the same manner as the class 5 nominal prefix, resulting in -za:--

(21) $-r_{\mathfrak{l}}+a->-z i ́+a->$-zâ:-

Comparison of the RF formative with the class 5 prefix gains further support from Runyankore, the neighboring language to the north. There we find that spirantization of the class 5 prefix did not occur in vowel-initial nominals, as illustrated in (22).

$$
\text { erí-ifo 'eye' Runyankore J11 }
$$

Nor did the RF formative undergo spirantization even though the same conditions existed in Runyankore (23) as those proposed for Kinyarwanda. That is, both formatives, $-r_{\mathfrak{l}}-$ and $-a-$, were present. 
In sum, the evidence points to an earlier period in Kinyarwanda in which there existed a formative -rí,- associated with remote future reference. Subsequent incorporation of -a- led to spirantization of the $/ r /$ and lengthening of the vowel /a/. This alternative hypothesis accounts for all the suspicious problems noted with the 'come' hypothesis and provides a coherent and plausible explanation commensurate with the data observed. Nevertheless, there are some indirect indications that $-r_{j}$ - may not have been an original formative in proto-Bantu as implied in Guthrie's reconstruction of ${ }^{*}$-di-.

\section{An Alternative History of $-r \hat{\jmath}-$}

In two zone $\mathbf{J}$ languages on the eastern side of Lake Victoria, Kikwaya (J25) in Tanzania and Luyia (J32) in Kenya, we find a peculiar aberrancy in the form of first person subject prefixes. In Kikwaya there are three future formatives. Relevant to our study is the similarity in form between the near future formative -la- and the remote future formative -li-. Depending on which is present, the form of the first person singular subject prefix differs, as illustrated in (24) and (25). (Through a regular phonological process in Bantu languages / $/ /$ becomes $[d]$ immediately following a nasal.)
a. ni-la-kol-e 'I will do' (near future)
Kikwaya
[Sillery 1932]
b. n-da-kol-e
a. ni-li-kol-a
'I will do' (remote future)
Kikwaya
b. *n-di-kol-a / *ndi-li-kol-a

In the near future construction two forms of the $1 \mathrm{~S}$ prefix are found, ni- or $n$-. However, when the construction incoprorates the RF formative, only the nisubject prefix is acceptable. A similar phenomenon is found in Luyia, as reported by Appleby [1961]. Normally the first person singular is indicated by en-, with some regular phonological variations resulting in deletion of the $/ n /$. However, with the remote future formative the form becomes ndi- (26).
a. ndi-li-khol-a
'I will do' (remote future)
Luyia
b. *en-di-khol-a 
Why should the simple (e)n-form of the first person subject prefix be precluded in these languages in juxtaposition with the remote future formative $-l i-$ ? A likely answer is that $-l i$ - is not the original canonical form of this formative. Rather, the RF must have had (at least) the form -Vli- at an earlier stage, and it is this form that constituted the original motivation for the nonoccurrence of the (e)n-form. If the $1 \mathrm{~S}$ subject prefix was originally of the form *ni- or *ndi-, as reconstructed by Guthrie [1971], then reduction to nasal alone only occurred before $\mathrm{C}$-initial formatives such as -la-. This suggests that the remote future formative must have had an initial vowel, probably $* / i /$. If, on the other hand, the 1S prefix was a nasal alone, as suggested in Meeussen [1967], reanalysis of a RF sequence nili- as $n i+l i$ - (rather than as $n+i l i-$ ) and extension of the $n i$ - form to other constructions would also account for the distribution noted. In either case the analysis of $-l i$ - as a reduced form of -ili-is significant. Is this -ili- a canonical, underived form, or is it derived from some auxiliary verb, for example? Consideration of morpho-syntactic phenomena in several contiguous zone $\mathrm{J}$ languages suggests that it is analyzable as composed of two parts.

In Botne [1989] I have argued that the RF formative in the J40 languages (Kikonzo J41 and Kinande J42) originated in the auxiliary verb -gind- 'want'. More specifically, the RF formative developed out of a particular form of this verb, -(g)ind-il-i-a [-indisya-]. Note the suffix /- $j$-/ here. Both Mashi (J53) and Nyanga (D43), languages located just south of Kikonzo and Kinande, incorporate a final /i/ (from $*_{j}$ ) in some future constructions (27-28).

rhw-aa-gend-i-sunik-a Mashi J53

1P-F-go-push

'we are going to push'

(28)

tw-a-kinduk-i

Nyanga D43 [Mateene 1980]

1P-F-cross

'we will cross (one day)'

As we can see in Mashi, a periphrastic construction with what seems to have been an /i/ suffix from the auxiliary has become a grammaticalized verbal form. This phenomenon resembles what we have observed in Kikonzo and Kinande. These data suggest that the final -a-in the Kinande/Kikonzo future has been added to the verbal expression as it was in Runyankore/ Lunyoro and Kinyarwanda, languages that are contiguous with them. Moreover, they suggest that our hypothesized form -il $j_{-}$can be analyzed as $-i l+j^{-}$, that is, root plus suffix. A supporting 
argument for this analysis of root plus suffix can be adduced from the RF in Giha. Unlike Kinyarwanda and Kirundi where we find -za:- and -zo:-, respectively, there appears to be no evidence of spirantization in the RF formative, which is -ro-. Given the closeness of these languages and the pervasiveness of spirantization in this region, how can we explain this? Since Giha underwent spirantization of the class 5 nominal prefix as noted for Kinyarwanda above, we must conclude that Giha did not make use of the $i$ suffix in these constructions, employing -a instead. Coalesence of auxiliary final $-a$ and infinitive initial $(k) u$ - of a periphrastic construction resulted in -ro- (see next section for discussion).

Additional evidence can be adduced from Chigogo (G11). In Botne [1988] I suggest that the future formatives in Chigogo (as in 30) most plausibly derive from an earlier periphrastic construction composed of auxiliary -hila 'want' plus the infinitive (-hila from *-pila). ${ }^{1}$

$$
\begin{array}{lll}
\text {-hila ku-root > -hilo-root > -olo-root (RF); -o-root (NF) } & \text { Chigogo G11 } \\
\begin{array}{lll}
\text { a. n-o-saga matama } & \text { 'I will grind (some) maize' (NF) } & \text { Chigogo G11 } \\
\text { b. n-olo-panta matama } & \text { 'I will plant (some) maize' (RF) }
\end{array}
\end{array}
$$

Kinyarwanda and the other $\mathrm{J}$ languages have undergone weakening of ${ }^{*} p$ to [h]. Thus, it seems quite plausible that an auxiliary verb *-pil- 'want' was the source of the remote future. From an original periphrastic construction in which the final vowel of the auxiliary was the suffix [i] (a syntactic type that no longer exists in most of the $\mathrm{J}$ languages) came a grammaticalized formative - $l i$ - in sevenvowel systems, -li- in five-vowel systems.

$$
\begin{array}{lll}
\text { (31) } * \text {-pil-i ku-root }>-h i l-i \text { ku-root }> & \text {-li-root } & \text { (5-vowel languages) } \\
& -1 j \text {-root } & \text { (7-vowel languages) }
\end{array}
$$

In Kinyarwanda, which added the -a- formative, the final result is -za:-, rather than $-l i$-. Thus, while the data directly support an earlier stage of $-l i-$, indirectly they suggest that this form may have been dervied from an even earlier auxiliary

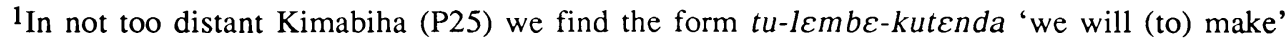
(remote future) in which $l \varepsilon m b \varepsilon$ - is the grammaticalized form of the infinitive $k u$-lembela 'to want'. This appears to be a derived stem, from $-l i-m b \varepsilon l-a$, where the prefix $-l i$ - is an intransitivizer/reflexivizer. In closely related Kimakua (P31) we find what appears to be a cognate form -li-pel-a 'to expect, hope'. *mb became $[p]$ in Kimakua. Thus, Chigogo -hila 'want' would appear to be cognate with the verbs in these two languages, with $/ p /$ ultimately becoming weakened to $/ h /$.
} 
verb, most plausibly a verb 'want'. Let us turn now to consideration of the form -zo:- in Kirundi and -ro- in Giha.

\section{Evolution of Kirundi -zo:- and Giha -ro-}

Considering the close linguistic relationship among Kinyarwanda, Kirundi and Giha, we might expect to find reflexes of the remote future in Kirundi and Giha similar to that found in Kinyarwanda. In Kirundi we do: Kirundi -zo:- differs from Kinyarwanda -za:- only in vowel quality. In Giha, however, the RF formative is -ro- .

The obvious link between the formatives in Kirundi and Giha is the vowel quality. This is not a trivial observation because there are no other languages in zone $\mathrm{J}$ that have verbal formatives with $/ o /$. There are such languages in zone $\mathrm{G}$ and, significantly, these formatives are associated with future reference (see map 4).
a. n-o-bita
1S-F-go
Chigogo (G11) [Cordell 1941]
'I will go (near future)'
b. n-olo-bita
1S-RF-go
'I will go (remote future)'
a. n-o-yula tsinowo
$1 \mathrm{~S}-\mathrm{Pr} / \mathrm{F}$-buy bananas
Luguru (G35)
[Nurse 1979b]
'I am buying/will buy bananas'

b. tu-tso-yula tsinowo

1P-RF-buy bananas

'we will buy bananas (remote)'

(34)

n-o-gula $\quad \eta^{h} O o$

Kizalamo (G33) [Nurse 1979b]

1S-Pr/F-buy bananas

'I am buying/will buy bananas'

A common source of $/ o$ / in verbal formatives in Bantu is contraction/coalesence of final -a of an auxiliary verb and initial $\mathrm{ku}$ - of the infinitive in a periphrastic construction. As mentioned in the previous section, for Chigogo, a zone $G$ 
language, my suggestion (presented in Botne [1989]) is that the remote future derives from such a process involving an auxiliary formative -hila 'want' (see 29). A similar process in Giha would account for the presence of the form -ro-. Unlike Kinyarwanda and Kirundi the RF formative in Giha did not undergo spirantization since we find $/ r /$, rather than $/ z /$, even though spirantization of $/ \mathrm{r} /$ occurred with the class 5 nominal prefix as it did in both Kinyarwanda and Kirundi. Thus, there would have been a different vowel, undoubtedly [a]. An auxiliary verb ending in -a would be in position to combine with $k u$ - to produce $/ o /$, a common change in eastern Bantu languages. If we assume that incorporation of prefixal -a- into Kirundi and Kinyarwanda preceded coalesence of -a and $k u$-, then we have a viable case for Kirundi as the intersection of the two processes (see map 5).

What these data suggest, then, is that the three J61 languages illustrate the intersection of three different historical developments: (1) utilization of the suffix $-j$ on an auxiliary verb; (2) spirantization of $/ r /$ to $/ z /$ when it occurs before $/ \mathrm{i} /$; and (3) contraction/coalesence of auxiliary final -a and infinitive initial $\mathrm{ku}$ - to $/ \%$. The relationship of these three developments in the languages under consideration is outlined in (35), at the top of the next page (note that there is no distinction between $/ 1 /$ and $/ r /$ in these languages).

This analysis of Giha -ro-gains support from the analysis of the Chigogo RF formative. In Botne [1988] I have argued that Chigogo and Giha are close genetic relatives and were once areal neighbors. Given that Giha and Chigogo are the only languages in east Africa manifesting the RF formative with -ro-/-lo-, it is not surprising to find that they have undergone the same development of an auxiliary. At this point it is not clear where certain innovations arose nor why they might have spread, nor is it apparent when the loss of initial hi- might have occurred. What is clear from the distribution of these different developments is that they intersect in J61, apparently resulting in different forms of the remote future formatives that otherwise would be expected to be more similar. 


\begin{tabular}{|c|c|c|c|}
\hline Kinyarwanda & Kirundi & Giha & \\
\hline--- & $\cdots$ & -hil-a ku- & -a final aux \\
\hline$-h i l-j k u-$ & $-h i l-j k u-$ & -- & $-i$ final aux \\
\hline -hiz-a:-ku- & -hiz-a:-ku- & -- & $\begin{array}{l}\text { incorporation of }-a-; \\
\text { spirantization }\end{array}$ \\
\hline-- & -hiz-o:- & $-h i l-o-$ & contraction/coalesence \\
\hline -hiz-a:- & -- & -- & loss of $k u$ - \\
\hline -za:- & $-z o:-$ & $-10-$ & $\begin{array}{l}\text { (phonological loss of } \\
-h i-\text { ) }\end{array}$ \\
\hline
\end{tabular}

\section{Summary and Conclusion}

Traditionally, the source of the remote future formative in J61 has been considered to be the verb $k u$-:za 'to come', an analysis which presented several problems. Evidence from different zone $\mathrm{J}$ languages supports the hypothesis that the remote future formative in various languages of zone $\mathrm{J}$, including $\mathrm{J} 61$, is a reflex of $-1 j$-, which itself may be derived from an auxiliary verb *-pila 'want'. Exceptions to this are the languages of J40 and J50 and Orusyan (J36) in which the RF formative has developed from different auxiliaries.

An alternative hypothesis put forward here-that $-l i$ - evolved from an auxiliary verb *-pila 'want'-is based on indirect and circumstancial evidence, there being no instance of this auxiliary plus infinitive in any of the languages in question. Thus, while we can confidently conclude that the remote future formative in J61 had an earlier form $-1 j$-, we need to gather further evidence supporting (or refuting) the auxiliary 'want' hypothesis. Nevertheless, the hypothesis is warranted on the strength of the answers it provides to a number of problems in variation and distribution of forms found in the J61 area, presenting a coherent picture of the interaction of several linguistic processes observed there.

If we are to make accurate comparative studies, reasonable reconstructions of verbal formatives and satisfactory classifications of languages and their movements, then we need to question some of the assumptions about morphological development that have been around for generations. While 'come' as an auxiliary verb may, indeed, be the source of future tense formatives in some Bantu languages, we cannot, automatically and without detailed analysis, assume that because the form (usually only the consonant) of the RF formative resembles that of the verb 'come' that the one is necessarily derived from the 
other. In many instances we simply have a case of convergent phonological evolution. We need to go back and look again at languages like Luguru, for example, and provide evidence for an analysis one way or another. 
Map 1. Eastern Bantu Zones

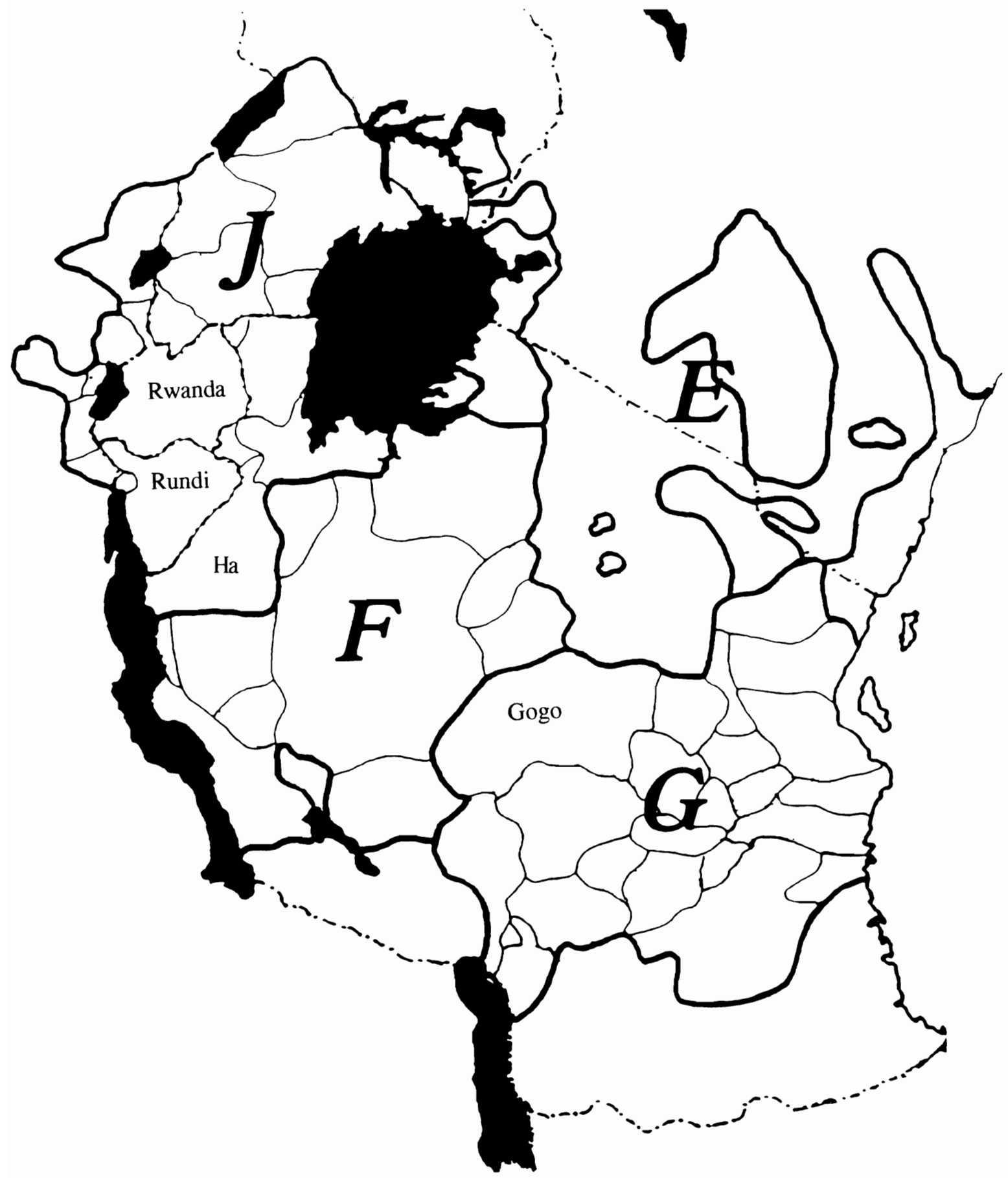


Map 2. Distribution of RF /o/ formatives

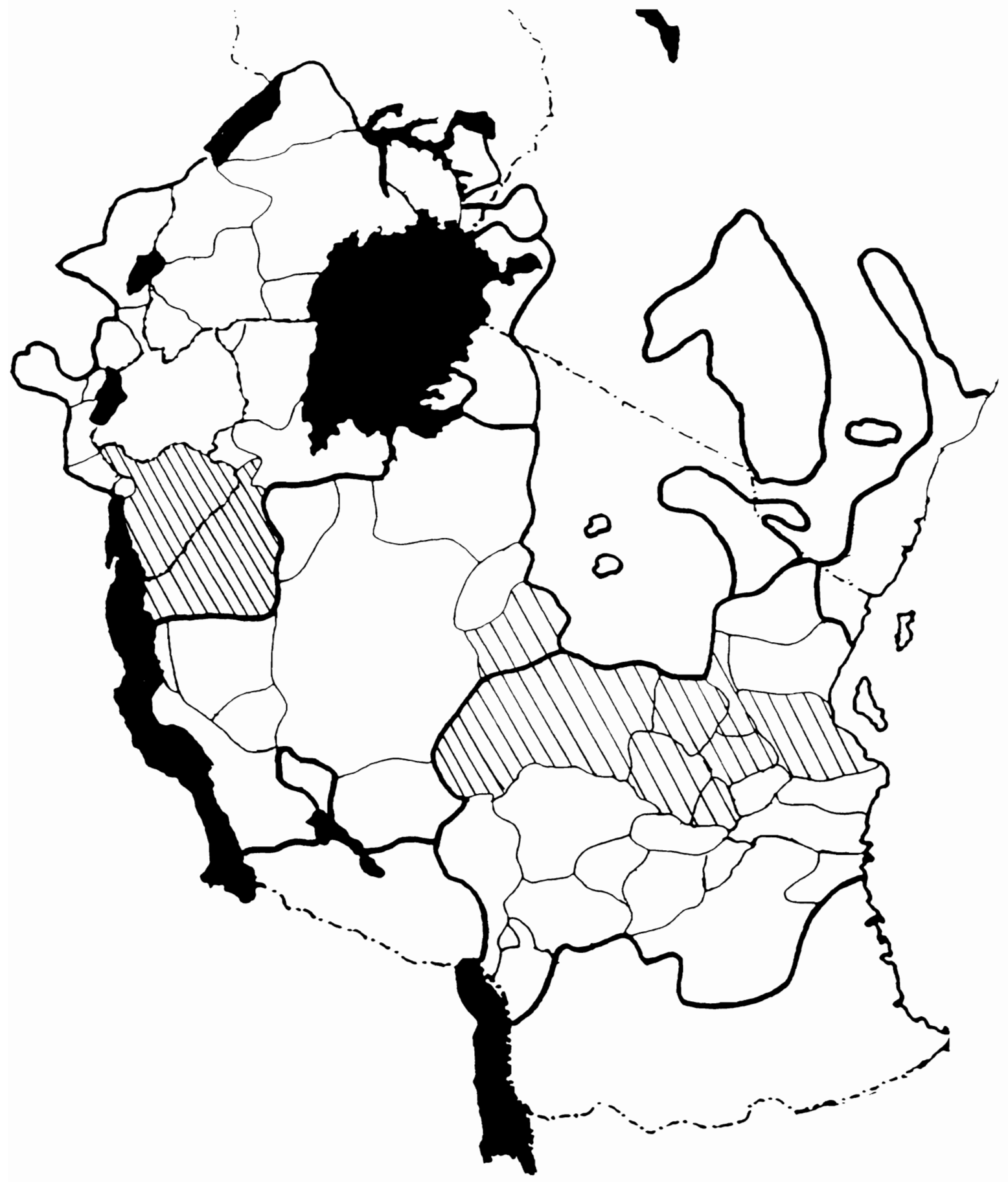


Map 3. Distribution of -ka-formative (past)

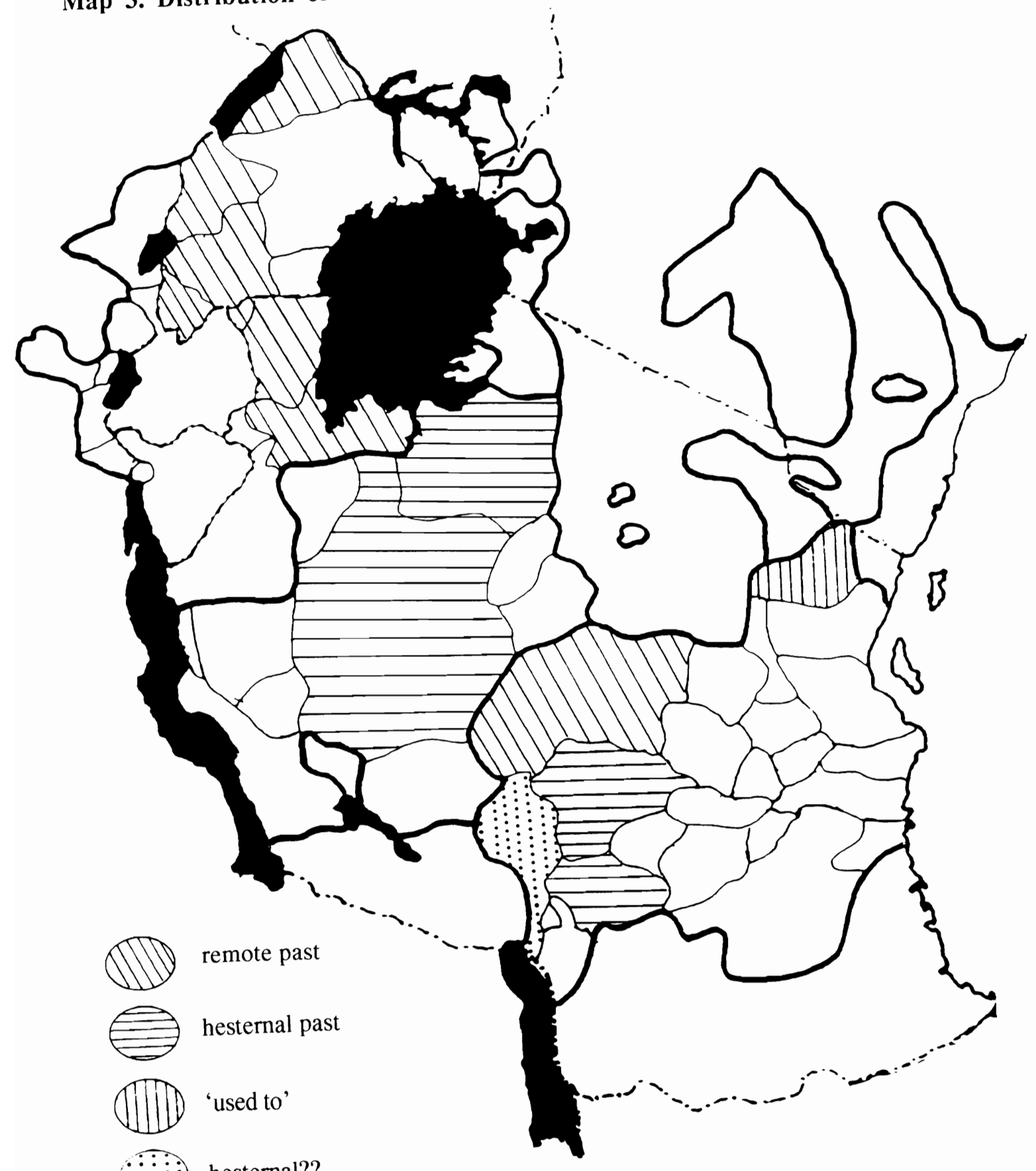

: hesternal?? 

Map 5. Suggested historical relationship of Cigogo to Giha \& Ruzinza

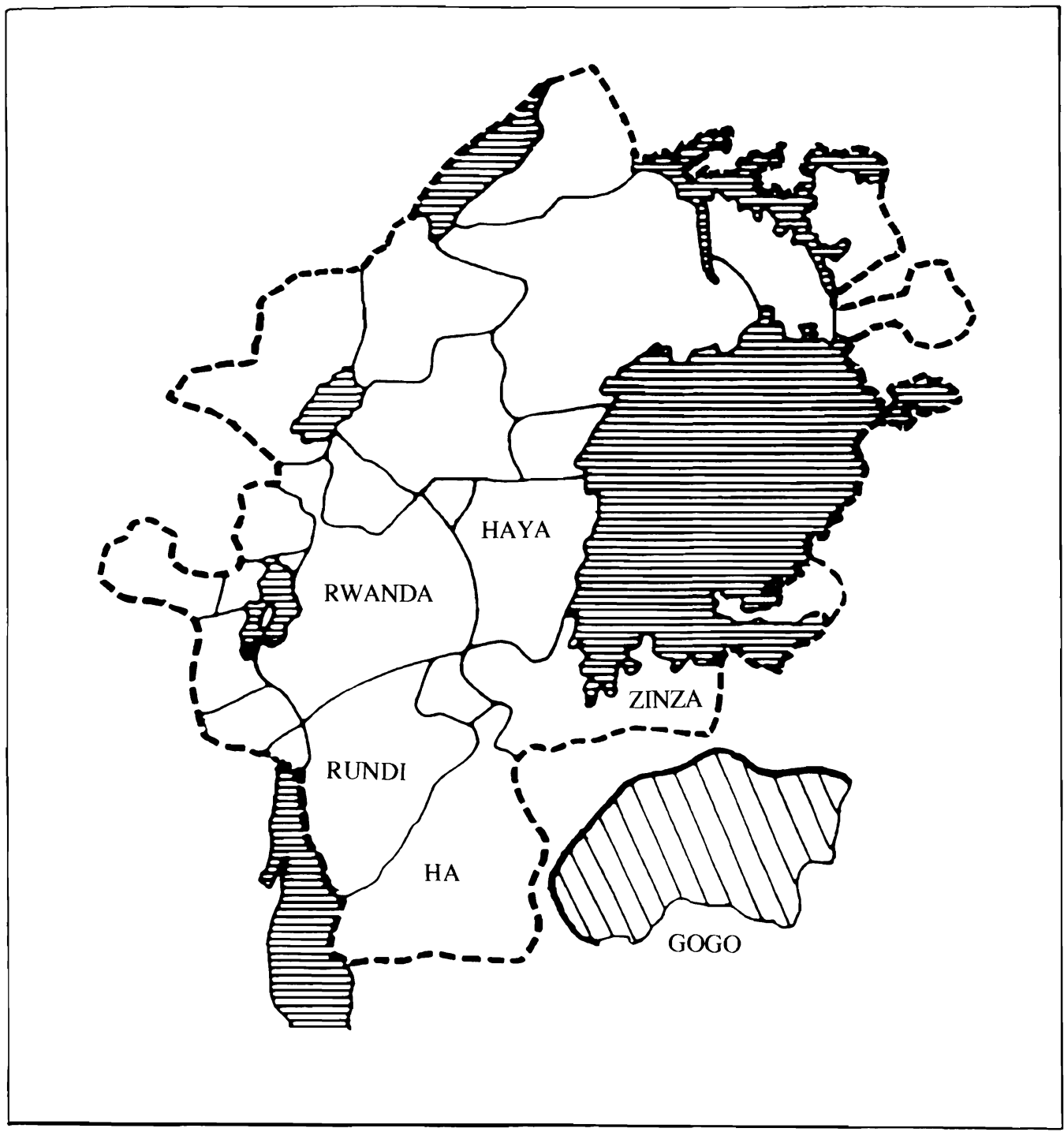




\section{REFERENCES}

Appleby, L.L. 1961. A First Luyia Grammar. Nairobi: East African Literature Bureau.

Ashton, E.O. et al. 1954. A Luganda Grammar. London: Longmans, Green and Co.

Bastin, Yvonne. 1978. "Les langues bantoues." In Daniel Barreteau (ed.) Inventaire des Etudes Linguistiques, pp. 123-185. Paris: Conseil International de la Langue Française.

Botne, Robert. 1983. "The semantics of tense in Kinyarwanda." Studies in African Linguistics 14:235-263.

Botne, Robert. 1988. "The historical relation of Cigogo to zone J languages." Paper presented at the 18th Conference on African Linguistics at Boston University.

Botne, Robert. 1989. "Reconstruction of a grammaticalized auxiliary in Bantu.' Studies in the Linguistic Sciences 19:169-186..

Cordell, O.T. 1941. A Gogo Grammar. Mpwapwa: n.p.

Givón, Talmy. 1969. Studies in Chibemba and Bantu Linguistics. Studies in African Linguistics, Supplement 3.

Guthrie, Malcolm. 1971. Comparative Bantu, Vol. 2. Farnborough, England: Gregg International Publishers, Ltd.

Hetherwick, Alexander. 1914. A Practical Manual of the Nyanja Language. Nyasaland and Northern Rhodesia: African Lakes Corporation, Ltd.

Hinnebusch, Thomas J. 1981. "Northeast Coast Bantu." In Thomas J. Hinnebusch, Derek Nurse, Martin Mould (eds.), Studies in the Classification of Eastern Bantu Languages, pp. 21-126. Hamburg: Helmut Buske Verlag.

Hurel, Eugéne. 1911. "Manuel de langue kinyarwanda." Mitteilungen des Seminars für Orientalische Sprachen 14:1-159. 
Kimenyi, Alexandre. 1986. Review of Le Kinyarwanda, langue bantoue du Rwanda: études linguistiques. Journal of African Languages and Linguistics 8:177-189.

Mateene, Kahombo. 1980. Essai de Grammaire Générative et Transformationnelle de la Langue Nyanga. Kinshasa: Presses Universitaires du Zaire.

Meeussen, A.E. 1967. "Bantu grammatical reconstructions." Africana Linguistica III, pp. 79-121. Tervuren: Musée Royal de l' Afrique Centrale.

Morris, H.F. and B.E.R. Kirwan. 1972. A Runyankore Grammar. Kampala: East African Literature Bureau.

Mould, Martin. 1981. Greater Luyia. In Thomas J. Hinnebusch, Derek Nurse, Martin Mould (eds.), Studies in the Classification of Eastern Bantu Languages, pp. 181-256. Hamburg: Helmut Buske Verlag.

Nurse, Derek. 1979a. Classification of the Chaga Dialects. Hamburg: Helmut Buske Verlag.

Nurse, Derek. 1979b. "Description of sample Bantu languages of Tanzania." African Languages/Langues Africaines 5:1-150.

Overdulve, C.M. 1975. Apprendre la langue Rwanda. The Hague: Mouton.

Polak, Louise. 1983. "Le réfléchi en bantoue." In Africana Linguistica IX, Annales Sciences Humaines $N^{\circ} 110$, pp. 272-304. Tervuren: Musée Royal de l'Afrique Centrale.

Polak-Bynon, Louise. 1975. A Shi Grammar. Tervuren: Musée Royal de l'Afrique Centrale, Annales Sciences Humaines $N^{\circ} 86$.

Rehse, Hermann. 1912. 'Die Sprache des Baziba in Deutsch-Ostafrika.' Zeitschrift für Kolonialsprachen 3:1-33, 81-123, 201-229.

Sambeek. J. van. n.d. Petite Grammaire Kiha (mss.)

Sillery, Anthony. 1932. "A sketch of the Kikwaya Language." Bantu Studies 6:273-308. 
van der Burgt, J.M.M. 1902. "Eléments d'une grammaire kirundi." Mitteilungen des Seminars für orientalische Sprachen 5:1-108.

Watkins, Mark Hanna. 1937. A Grammar of Chichewa. Supplement to Language, $\mathrm{N}^{\circ} 24$.

Ziervogel, D. and R.S. Dau. 1961. A Handbook of the Venda Language. Pretoria: University of South Africa. 